Quim. Nova, Vol. 35, No. 1, 170-174, 2012

\title{
ANÁLISE DE ESPECIAÇÃO DE COBRE E ZINCO EMPREGANDO VOLTAMETRIA DE REDISSOLUÇÃO ANÓDICA COM PULSO DIFERENCIAL
}

\author{
Alessandra Emanuele Tonietto ${ }^{\#}$ Marco Tadeu Grassi* \\ Departamento de Química, Universidade Federal do Paraná, CP 19081, 81531-990 Curitiba - PR, Brasil
}

Recebido em 10/8/10; aceito em 3/6/11; publicado na web em 22/7/11

\begin{abstract}
SPECIATION ANALYSIS OF COPPER AND ZINC USING DIFFERENTIAL PULSE ANODIC STRIPPING VOLTAMMETRY This work describes methodologies for speciation analysis of the metals copper and zinc as total, total dissolved, labile, as well as complexation capacity (conditional stability constants and available ligand concentration), using the same technique, differential pulse anodic stripping voltammetry (DPASV). Several supporting electrolytes were tested, and the results showed that $\mathrm{KNO}_{3}$ and $\mathrm{HNO}_{3}$ resulted in voltamograms without interferences as well as excellent resolution for the total and labile fractions. The methodology using the DPASV technique allows a simple and low cost analysis of copper and zinc speciation, with high precision and sensitivity, with limits of quantification (LOQ) of $1.8 \mathrm{nmol} \mathrm{L}^{-1}$ for copper and $2.1 \mathrm{nmol} \mathrm{L}^{-1}$ for zinc.
\end{abstract}

Keywords: anodic stripping voltammetry; speciation; trace metal.

\section{INTRODUÇÃO}

Estudos de especiação de metais são de grande importância para a avaliação de impactos ambientais, avaliações ecotoxicológicas, assim como para o entendimento do comportamento e destino dos metais em ambientes aquáticos. ${ }^{1}$ Informações sobre a reatividade, mobilidade e biodisponibilidade dos metais em águas naturais podem ser obtidas mediante estudos de especiação. A relação entre especiação dos elementos metálicos e toxicidade aos organismos é complexa e depende não somente da espécie química em questão, mas também do organismo exposto e da função fisiológica que o elemento metálico exerce no organismo. ${ }^{2}$ Sabe-se que os elementos cobre e zinco são essenciais aos organismos aquáticos, mas podem ser tóxicos quando encontrados em concentrações mais elevadas. ${ }^{3}$ Devido à complexidade da interação metais-organismo-ambiente, o uso de técnicas analíticas capazes de determinar diferentes espécies químicas com baixa manipulação amostral, tal qual a voltametria, assume destaque quanto à compreensão da dinâmica dos metais no ambiente.

Sabe-se que o papel biogeoquímico dos metais correlaciona-se com suas formas físico-químicas, as quais incluem espécies associadas ao material particulado, coloidal e dissolvido., ${ }^{3,4}$ Portanto, avaliar a concentração total de um metal é insuficiente para inferir sobre seu comportamento e destino no ambiente, assim como sobre seus impactos na biota aquática. ${ }^{1,3,5}$ Alguns autores consideram que espécies lábeis apresentam maior biodisponibilidade aos organismos aquáticos. ${ }^{6}$ Por outro lado, metais complexados a ligantes orgânicos são considerados de menor biodisponibilidade. ${ }^{7}$

A matéria orgânica dissolvida (MOD) exerce um papel fundamental na especiação dos metais-traço; os ligantes orgânicos possuem poder de complexação com metais, ${ }^{8}$ cuja força de associação e quantidade de ligantes disponíveis variam com a categoria da MOD..${ }^{910} \mathrm{Os}$ estudos de especiação de metais podem ser realizados empregando-se diferentes abordagens e técnicas analíticas tais como a voltametria de redissolução anódica (DPASV) e voltametria de redissolução catódica (DPCSV), ambas com detecção por pulso diferencial, espectrometria de massa com plasma indutivamente acoplado (ICP-MS), difusão em

*e-mail: mtgrassi@ufpr.br

"Endereço atual: Departamento de Química, Universidade Federal de São Carlos, CP 676, 13560-970 São Carlos - SP, Brasil filmes finos por gradiente de concentração (DGT), espectrometria de absorção atômica (AAS) e outras. A principal vantagem da voltametria em relação às outras técnicas é a possibilidade de análise da amostra com pouco ou nenhuma etapa de extração e/ou separação. Essas etapas aumentam os riscos de contaminação e de alteração das espécies químicas presentes, consequentemente são gerados erros na determinação da concentração dos metais. Além disso, a voltametria apresenta como vantagens custos relativamente baixos ${ }^{3}$ e capacidade para detectar elementos-traço em concentrações normalmente presentes no ambiente, e.g., concentrações da ordem de $10^{-11}-10^{-12} \mathrm{~mol} \mathrm{~L}{ }^{-1}$. Portanto, a voltametria é capaz de fornecer dados quantitativos com excelentes limites de detecção e elevada sensibilidade analítica, ${ }^{11,12}$ além de apresentar boa correlação com a disponibilidade biológica da espécie metálica. ${ }^{1,13}$

Diversos métodos voltamétricos têm sido usados para análises de especiação de metais mas, em muitos casos, diferentes técnicas voltamétricas são usadas para os diferentes elementos. Tem-se, por exemplo, que a especiação do cobre em águas naturais é frequentemente efetuada através da competição de ligantes com determinação por DPCSV, enquanto que para o zinco normalmente DPASV é usada. ${ }^{1,14-19}$

Skoog et al.,${ }^{20}$ Harris $^{21}$ e Wang ${ }^{22}$ relataram que a faixa de trabalho na voltametria é dependente não apenas das características do eletrodo de trabalho, mas igualmente do meio em que ele está imerso. Frequentemente, a faixa de trabalho é limitada por dois processos eletródicos. O primeiro deles, em potenciais mais positivos, está representado pela ocorrência de correntes relativamente elevadas, devido à oxidação da água para formar moléculas de oxigênio. Em potenciais negativos, por outro lado, correntes significativamente elevadas são geradas em função da redução da água para formar hidrogênio. ${ }^{22}$ Outra possibilidade de interferência, no caso de análises voltamétricas baseadas na redissolução anódica, diz respeito à possível oxidação do mercúrio, que ocorre de $+0,25 \mathrm{~V}^{21,22} \mathrm{a}+0,4 \mathrm{~V},{ }^{20}$ que também produz correntes de magnitudes consideráveis. Essa propriedade limita severamente o uso do eletrodo de mercúrio na região positiva de potencial. $\mathrm{Na}$ região onde os potenciais são maiores que $+0,4 \mathrm{~V}$, ocorre a formação de mercúrio(I), originando uma onda que mascara as curvas de outras espécies que podem sofrer oxidação. Na presença de íons que formam precipitados ou complexos com mercúrio(I), esse comportamento ocorre mesmo em potenciais ainda mais baixos. ${ }^{20}$ 
Além disso, um tipo especial de interferência ocorre na ASV como resultado da formação de complexos intermetálicos no eletrodo de mercúrio. Esses compostos intermetálicos causam diminuição das correntes e deslocamento de potenciais de pico. A interferência mais comum é observada na diminuição do pico do zinco quando há excesso do cobre em relação àquele metal. Entretanto, em análises de água, isso é um problema raro, porque a concentração dos metais é baixa, e o zinco, frequentemente, está presente em excesso ao cobre. Tyszczuk et al. ${ }^{23}$ estudaram a interferência da formação dos complexos intermetálicos $\mathrm{Cu}-\mathrm{Zn}$ e observaram que zinco é mensurável na presença de até 10 vezes a concentração de cobre.

Ruzic ${ }^{24}$ propôs um método para a interpretação direta da titulação de águas naturais com metais. O método baseia-se na construção de um gráfico que relaciona a razão entre a concentração do metal na forma lábil e a concentração do metal complexado vs. a concentração do metal lábil. A aplicação do método se baseia na complexação do metal pelos ligantes presentes na amostra considerando uma estequiometria 1:1. Este modelo fornece as características de complexação dos metais através da aplicação da Equação 1, conhecida como linearização de Ruzic. ${ }^{24}$

$$
\frac{\left[\mathrm{M}^{\prime}\right]}{[\mathrm{ML}]}=\frac{1}{\mathrm{~K}^{\prime} \cdot \mathrm{C}_{\mathrm{L}}}+\frac{1}{\mathrm{C}_{\mathrm{L}}} \cdot\left[\mathrm{M}^{\prime}\right]
$$

[M']: metal lábil; [ML]: metal complexado; K': constante de estabilidade condicional metal-ligante; $\mathrm{C}_{\mathrm{L}}$ : concentração de ligantes disponíveis.

Como mostra a Equação 1, para a obtenção das características de complexação, constrói-se um gráfico de [M']/[ML] vs. [M']. A equação da reta obtida através do gráfico de $\left[\mathrm{M}^{\prime}\right] /[\mathrm{ML}]$ vs. [M'] fornece os coeficientes angular e linear que correspondem aos valores de $1 / C_{L}$ e $1 / K^{\prime} \cdot C_{L}$, respectivamente. Esse modelo fornece quatro características de complexação, ou seja, a constante de estabilidade condicional ( $\left.\mathrm{K}^{\prime}\right)$, a concentração de ligantes disponíveis $\left(\mathrm{C}_{\mathrm{L}}\right)$, a concentração do metal complexado ([ML]) e a concentração do mesmo metal na forma lábil ([M']).

Xue et al. ${ }^{19}$ estudaram a especiação do cobre e zinco em amostras de água de um ambiente eutrofizado empregando a DPCSV para cobre e catecol como ligante de competição. Para o zinco, os autores usaram DPASV e competição de ligantes. Velasquez et al. ${ }^{16}$ apresentam um estudo da especiação de cobre e zinco através de voltametria, com redissolução catódica para cobre e redissolução anódica para zinco.

Através de um estudo de comparação de métodos analíticos para análise da especiação de cobre e zinco, Meylan et al. ${ }^{15}$ compararam a técnica de DGT na determinação de cobre e zinco lábeis com competição por troca de ligantes e voltametria de redissolução anódica para o zinco, e voltametria de redissolução catódica para cobre. A fração total dissolvida de ambos os metais foi determinada através de ICP-MS. Os autores confirmaram que técnicas baseadas em princípios distintos detectam quantidades de metais distintas. Variações das frações lábeis na ordem de 9,4-100 $\mathrm{nmol} \mathrm{L}^{-1}$ para cobre e 29-222 nmol L $\mathrm{L}^{-1}$ para zinco foram obtidas pelos autores.

O presente trabalho consiste da implantação de um método para a análise de especiação de cobre e zinco em amostras de águas naturais. Neste trabalho efetuou-se um estudo utilizando $\mathrm{KCl}$ e $\mathrm{KNO}_{3}$ como eletrólitos de suporte para determinação da concentração lábil. Como descrito na literatura, ${ }^{25}$ a análise de cobre na presença de cloreto usando eletrodo de mercúrio não é ideal. Ao empregar-se $\mathrm{KNO}_{3}$ o potencial de pico do cobre apresentou seu valor máximo em aproximadamente $0,0 \mathrm{~V}$ favorecendo um perfil mais simétrico do pico. Assim, as determinações das concentrações lábeis de cobre e zinco foram realizadas usando $\mathrm{KNO}_{3}$ como eletrólito de suporte. Resultados semelhantes foram obtidos com $\mathrm{HNO}_{3}$. O método está fundamentado no emprego da DPASV para dois metais e alcança limites de detecção compatíveis com a concentração de metais normalmente encontrada nos ecossistemas aquáticos, e.g., concentrações totais inferiores a $10^{-7}-10^{-8} \mathrm{~mol} \mathrm{~L}{ }^{-1}$, chegando até $10^{-11} \mathrm{~mol} \mathrm{~L}^{-1}{ }^{3,20}$

\section{PARTE EXPERIMENTAL}

\section{Reagentes e soluções}

As soluções foram preparadas diariamente utilizando água do tipo Milli-Q (Millipore). Nitrato de potássio, cloreto de potássio (Merck, Alemanha), ácidos nítrico e clorídrico (Fluka), todos de grau analítico, foram avaliados como eletrólito de suporte. As soluções padrão dos metais cobre e zinco foram preparadas a partir de diluição serial de soluções comerciais $1000 \mathrm{mg} \mathrm{L}^{-1}$ (Titrisol, Merck).

\section{Equipamentos e parâmetros experimentais}

As determinações voltamétricas foram realizadas empregando um potenciostato (EG\&G Model 394) acoplado a um sistema de eletrodos (EG\&G Parc, Model 303A, SMDE) utilizando o modo gota pendente de mercúrio (HMDE). Os parâmetros da análise voltamétrica foram: potencial de deposição $-1,2 \mathrm{~V}$ ( $v s . \mathrm{Ag} / \mathrm{AgCl}, \mathrm{KCl}{ }_{\text {(sat.) }}$ ); potencial inicial -1,2 V; potencial final +0,15 V; tempo de deposição de $300 \mathrm{~s}$ para fração total (recuperável e dissolvida) e 600 s para a fração lábil; amplitude do pulso de $50 \mathrm{mV}$; velocidade de varredura de $8 \mathrm{mV} \mathrm{s}^{-1}$; purga inicial com $\mathrm{N}_{2}$ durante $600 \mathrm{~s}$ e purga entre as adições por $180 \mathrm{~s}$.

\section{Amostras de água}

As amostras de água natural foram coletadas no Reservatório do Iraí, ambiente eutrofizado, localizado na Região Metropolitana de Curitiba (RMC) (Paraná). O Reservatório do Iraí foi construído para armazenar 52 milhões de $\mathrm{m}^{3}$ de água, em 14,6 km² de área inundada, com profundidade média de $5 \mathrm{~m}$. É responsável pelo abastecimento de mais de $60 \%$ da população da RMC e desde o término do seu enchimento, em 2001, sofre um contínuo processo de degradação ambiental, que afeta a qualidade de suas águas.

Devido às baixas concentrações dos metais cobre e zinco nas amostras, todos os procedimentos de coleta, preservação e análise das amostras foram fundamentados no protocolo de técnicas limpas..$^{26,27}$

O metal presente na fração total recuperável (TR) corresponde à concentração total presente na amostra não filtrada, enquanto o metal total dissolvido (TD) é aquele presente na fração dissolvida, operacionalmente definida como a fração que atravessa uma membrana de $0,45 \mu \mathrm{m}$ de diâmetro de poro. ${ }^{28,29} \mathrm{~A}$ fração lábil, presente na fração dissolvida, corresponde à soma de íons metálicos hidratados, associados a complexos fracos e adsorvidos fracamente nas partículas coloidais. $^{30}$

\section{Procedimento experimental para determinação de $\mathrm{Cu}$ e $\mathrm{Zn}$ na fração total recuperável}

Inicialmente foram realizados estudos para avaliar o melhor eletrólito de suporte para determinação dos metais na fração total. Para a escolha dos eletrólitos de suporte nas frações total recuperável e dissolvida, foram utilizados $10 \mathrm{~mL}$ dos padrões de cobre $\left(\mathrm{CuCl}_{2} \mathrm{em}\right.$ $\mathrm{H}_{2} \mathrm{O}$, Titrisol Merck) $\left(78 \mathrm{nmol} \mathrm{L}{ }^{-1}\right)$ e zinco $\left(\mathrm{ZnCl}_{2}\right.$ em $0,06 \% \mathrm{HCl}$, Titrisol Merck) (76 nmol L-1) em $0,01 \mathrm{~mol} \mathrm{~L}^{-1}$ de $\mathrm{HNO}_{3}$ ou $\mathrm{HCl}$ e submetidos à análise voltamétrica, utilizando-se o método de adição de padrão. As concentrações finais do padrão obtidas na célula eletroquímica foram de 77,9/75,6, 154,2/149,6 e 302,6/293,6 nmol L-1 para cobre e zinco, respectivamente. 
Para a determinação da concentração total recuperável dos metais cobre e zinco, alíquotas das amostras in natura, foram digeridas utilizando o procedimento descrito por Sodré et al. ${ }^{31} \mathrm{O}$ procedimento de digestão baseia-se na ação da radiação ultravioleta gerada em um reator (UV LAB EL 10, Umex, Dresden, Germany) ativado por micro-ondas. Uma alíquota de $12 \mathrm{~mL}$ da amostra acidificada em $\mathrm{pH}$ 2,0 com $\mathrm{HNO}_{3}$ foi transferida para o reator, sendo em seguida adicionados $20 \mu \mathrm{L}$ de $\mathrm{H}_{2} \mathrm{O}_{2} 30 \%$ (grau analítico, Merck) e inserido em forno micro-ondas (Electrolux ME900). Durante a digestão foram empregados três ciclos de 2 min de irradiação, utilizando-se a potência máxima nominal do forno micro-ondas (900 W). Após os três primeiros ciclos de digestão foram adicionados 20 $\mu \mathrm{L}$ de $\mathrm{H}_{2} \mathrm{O}_{2} 30 \%$ (grau analítico, Merck) e, em seguida, realizados mais três ciclos de digestão, de 2 min cada. Um béquer contendo aproximadamente $1 \mathrm{~L}$ de água foi colocado no forno juntamente com o reator para dispersar o calor gerado e evitar perdas por ebulição da amostra. Entre cada ciclo de irradiação a água contida no béquer era substituída e o reator permanecia em banho de gelo por aproximadamente $20 \mathrm{~min}$. Um volume de $10 \mathrm{~mL}$ da amostra assim tratada foi submetido à análise voltamétrica, utilizando-se o método da adição de padrão. As concentrações finais do padrão obtidas na célula eletroquímica variavam a cada amostra determinada, mas em média os valores da adição foram de 15,30 e $45 \mathrm{nmol} \mathrm{L}^{-1}$ tanto para cobre, quanto para zinco.

\section{Procedimento experimental para determinação de $\mathrm{Cu}$ e Zn na fração total dissolvida}

Para a determinação de cobre e zinco na fração total dissolvida, $10 \mathrm{~mL}$ das amostras de água previamente filtradas em membrana 0,45 $\mu \mathrm{m}$ (Schleicher \& Shuell), foram submetidas à digestão fotoquímica de acordo com procedimento descrito por Sodré et al., ${ }^{31}$ porém foram realizados três ciclos de 2 min. Assim como na fração total recuperável, a amostra da fração total dissolvida foi tratada e submetida à análise voltamétrica, utilizando-se o método de adição de padrão.

\section{Procedimento experimental para determinação de $\mathrm{Cu}$ e $\mathrm{Zn}$ na forma lábil}

Para determinar as concentrações lábeis dos metais, a amostra foi mantida em $\mathrm{pH}$ natural, uma vez que mudanças de $\mathrm{pH}$ provocam alterações na distribuição das espécies metálicas, alterando, consequentemente, a especiação química dos metais. Por isso a importância de um eletrólito de suporte inerte na realização das medidas voltamétricas. Desta forma, foram conduzidos experimentos utilizando $10 \mathrm{~mL}$ de amostras de água natural empregando-se dois sais, $\mathrm{KNO}_{3}$ e $\mathrm{KCl}\left(0,01 \mathrm{~mol} \mathrm{~L}^{-1}\right)$ como eletrólito de suporte.

Para a determinação da fração lábil, $10 \mathrm{~mL}$ das amostras de água previamente filtradas em membrana $0,45 \mu \mathrm{m}$ (Schleicher \& Shuell) foram tituladas, separadamente para cada metal, com solução 7,87 $\mu \mathrm{mol} \mathrm{L}-1$ de cobre $\left(\mathrm{CuCl}_{2}\right.$ em $\mathrm{H}_{2} \mathrm{O}$, Titrisol Merck) e 7,63 $\mu \mathrm{mol} \mathrm{L} \mathrm{L}^{-1}$ de zinco $\left(\mathrm{ZnCl}_{2}\right.$ em $0,06 \% \mathrm{HCl}$, Titrisol Merck), registrando-se voltamogramas após cada adição do titulante, respeitando-se sempre um tempo prévio de contato de 20 min. ${ }^{6}$ Esse tempo de contato foi aguardado entre as determinações para que o metal adicionado fosse complexado pelos ligantes disponíveis na amostra. Através desse procedimento determinou-se, além da concentração do metal na forma lábil, a capacidade de complexação (CC) da amostra, que avalia a concentração de ligantes totais disponíveis $\left(\mathrm{C}_{\mathrm{L}}\right)$, e a constante de estabilidade condicional ( $\mathrm{K}^{\prime}$ ) dos complexos formados. ${ }^{6,24} \mathrm{Em}$ todos os procedimentos foi utilizada a mesma técnica para determinação das concentrações dos metais, DPASV. Todas as determinações dos metais foram realizadas em triplicata.

\section{RESULTADOS E DISCUSSÃO}

Para atestar a aplicabilidade do método proposto, utilizou-se duas amostras de água do Reservatório do Iraí coletadas em janeiro (amostra A) e maio (amostra B) de 2005 como exemplos para análise de especiação. A Figura 1 apresenta os voltamogramas obtidos para determinação de cobre e zinco na fração total dissolvida da amostra A, utilizando $\mathrm{HNO}_{3}$ como eletrólito de suporte. A partir dos voltamogramas, observa-se o perfil simétrico dos picos, resultando coeficientes de correlação satisfatórios para determinação dos metais na amostra, como apresentados na Tabela 1 . Assim, tendo-se realizado a titulação da amostra, para determinar a fração lábil e a $\mathrm{CC}\left(\mathrm{C}_{\mathrm{L}} \mathrm{e} \mathrm{K}^{\prime}\right)$, um gráfico foi construído a partir dos valores de correntes de pico $v s$. concentrações da espécie eletroativa, para cada adição de metal.

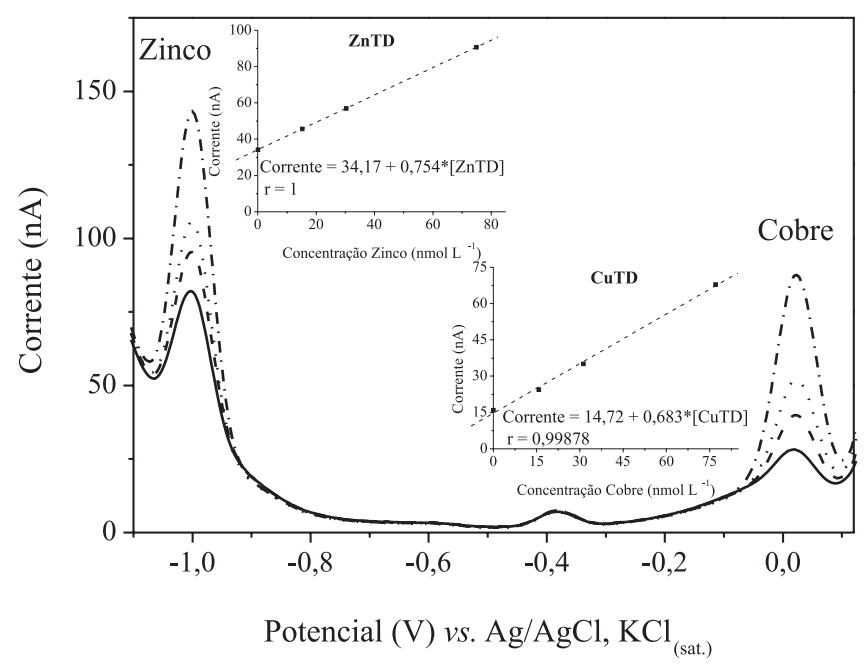

Figura 1. Voltamogramas referentes à adição de padrões de cobre e zinco na amostra A para determinação de cobre e zinco total dissolvido, utilizando $\mathrm{HNO}_{3}$ como eletrólito de suporte. (-) Amostra; Adições de Cobre/Zinco:

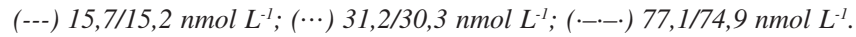
Condições experimentais: HMDE; $E_{\text {dep }}=-1,2 \mathrm{~V} ; E_{\text {inicial }}=-1,2 \mathrm{~V} ; E_{\text {final }}=+0,15$ $V$; amplitude do pulso $=50 \mathrm{mV}$; Velocidade de varredura $=8 \mathrm{mV} \mathrm{s}^{-1}$

Após a titulação da amostra separadamente para cada metal, constrói-se um gráfico, como apresentado na Figura 2, utilizandose os valores de intensidade de corrente de pico (nA) geradas após cada adição da solução titulante e as concentrações $\left(\right.$ nmol L $\left.{ }^{-1}\right)$ do metal total adicionado em cada ponto da titulação, considerando, em ambos os casos, a concentração do metal dissolvido já presente na amostra.

A partir dos comportamentos descritos nos gráficos, observa-se que no início da titulação praticamente todo o metal adicionado foi complexado por ligantes disponíveis na amostra, resultando numa variação negligenciável da corrente. Isso ocorre pois o metal complexado não é eletroativo ou o complexo formado apresenta um coeficiente de difusão muito menor do que aquele do íon livre, diminuindo assim a magnitude da corrente de pico. A partir de uma determinada concentração do metal adicionado, a corrente aumenta em proporção ao aumento da concentração do metal adicionado na amostra. Isto significa que após o tempo de contato de cada adição de metal (20 min), o metal lábil (eletroativo) é responsável pela corrente gerada. Após atingir a capacidade de complexação, todo o metal adicionado encontra-se na forma eletroativa. Tomando-se os pontos da faixa linear da curva de titulação, um novo gráfico é construído relacionando a corrente de pico (nA) em função da concentração total do metal $\left(\right.$ nmol L $\left.{ }^{-1}\right)$. A partir desses dados determinou-se o 
Tabela 1. Análise de especiação dos metais cobre e zinco e valores de capacidade de complexação (C $\mathrm{L}_{\mathrm{L}}$ e LogK') para amostras coletadas no Reservatório do Iraí

\begin{tabular}{|c|c|c|c|c|}
\hline & \multicolumn{2}{|c|}{ Amostra A (média \pm sd)* } & \multicolumn{2}{|c|}{ Amostra B $(\text { média } \pm \text { sd })^{*}$} \\
\hline & Cobre & Zinco & Cobre & Zinco \\
\hline $\operatorname{MTR}\left(n m o l ~ L^{-1}\right)$ & $26,3 \pm 2,5$ & $51,5 \pm 3,7$ & $17,4 \pm 2,5$ & $96,8 \pm 11,2$ \\
\hline $\operatorname{MTD}\left(\mathrm{nmol} \mathrm{L}^{-1}\right)$ & $20,0 \pm 2,2$ & $49,9 \pm 5,1$ & $15,1 \pm 0,7$ & $92,8 \pm 7,5$ \\
\hline ML (nmol L-1) & $14,1 \pm 1,5$ & $47,9 \pm 0,2$ & $10,6 \pm 1,1$ & $83,6 \pm 1,0$ \\
\hline Mlábil (nmol L-1) & $5,9 \pm 1,5$ & $2,0 \pm 0,2$ & $4,5 \pm 1,1$ & $9,2 \pm 1,0$ \\
\hline $\mathrm{C}_{\mathrm{L}}\left(\mathrm{nmol} \mathrm{L} \mathrm{L}^{-1}\right)$ & $143,6 \pm 11,5$ & $252,0 \pm 22,4$ & $142,9 \pm 11,4$ & $278,0 \pm 24,7$ \\
\hline $\log K^{\prime}$ & $7,6 \pm 0,2$ & $7,9 \pm 0,1$ & $8,0 \pm 0,2$ & $7,7 \pm 0,1$ \\
\hline
\end{tabular}

$\mathrm{MTR}=$ metal total recuperável MTD = metal total dissolvido; $\mathrm{ML}=$ metal complexado $\mathrm{C}_{\mathrm{L}}=$ concentração de ligantes disponíveis. * $\mathrm{n}=3 ;$ média \pm desvio padrão.

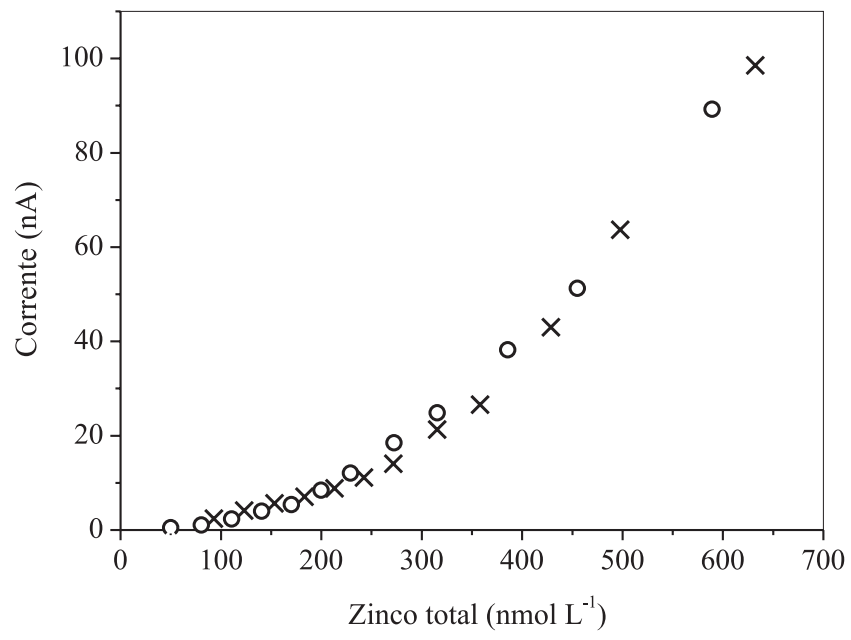

Figura 2. Curvas de titulação das amostras de água do Reservatório do Iraí (força iônica 0,01 mol L-1 em $\mathrm{KNO}_{3}$ ), (○) amostra A e (×) amostra $B$. (a) titulação com cobre (b) titulação com zinco. Condições experimentais: $H M D E ; E_{\text {dep. }}=-1,2 \mathrm{~V} ; E_{\text {inicial }}=-1,2 \mathrm{~V} ; E_{\text {final }}=+0,15 \mathrm{~V}$; amplitude do pulso $=$ $50 \mathrm{mV}$; velocidade de varredura $=8 \mathrm{mV} \mathrm{s} \mathrm{s}^{-1}$

valor do coeficiente angular da reta obtida, que foi usado no cálculo da fração lábil do metal para cada ponto da titulação. O cálculo da concentração do metal lábil é realizado através do quociente entre a corrente correspondente a cada ponto da região linear da curva, como mostrado na Equação 2.

$$
\left[\mathrm{M}^{\prime}\right]=\frac{\mathrm{ip}}{\mathrm{s}}
$$

[M']: metal lábil; ip: corrente de pico para cada adição de metal; s: slope (coeficiente angular).

As concentrações de cobre lábil e zinco lábil encontrados na amostra A foram de 5,9 $\pm 1,5$ e 2,0 $\pm 0,2 \mathrm{nmol} \mathrm{L}^{-1}$ e na amostra $\mathrm{B}$ foram de 4,5 $\pm 1,1$ e 9,2 $\pm 1,0 \mathrm{nmol} \mathrm{L}^{-1}$, respectivamente. De posse dos resultados determinou-se o valor da concentração do metal complexado através da diferença entre a concentração total do metal (metal total dissolvido originalmente presente na amostra somado ao metal adicionado) e a concentração do metal lábil, conforme a Equação 3.

$$
[\mathrm{ML}]=\mathrm{MTD}-\left[\mathrm{M}^{\prime}\right]
$$

[ML]: metal complexado; MTD: concentração de metal total dissolvido; [M']: metal lábil.

Através desta diferença entre o metal total dissolvido e o metal lábil, as concentrações de cobre complexado $(\mathrm{CuL})$ e zinco complexado $(\mathrm{ZnL})$ (Tabela 1) foram obtidas.
Através da construção do gráfico [M']/[ML] vs. [M'] (Figura 3) foram obtidos os parâmetros que compõem a Equação 1. Os valores correspondentes aos coeficientes angular e linear, a concentração de ligantes disponíveis, $\mathrm{C}_{\mathrm{L}}$, bem como a constante de estabilidade condicional para os complexos formados com cobre e zinco, LogK', foram então estimados.

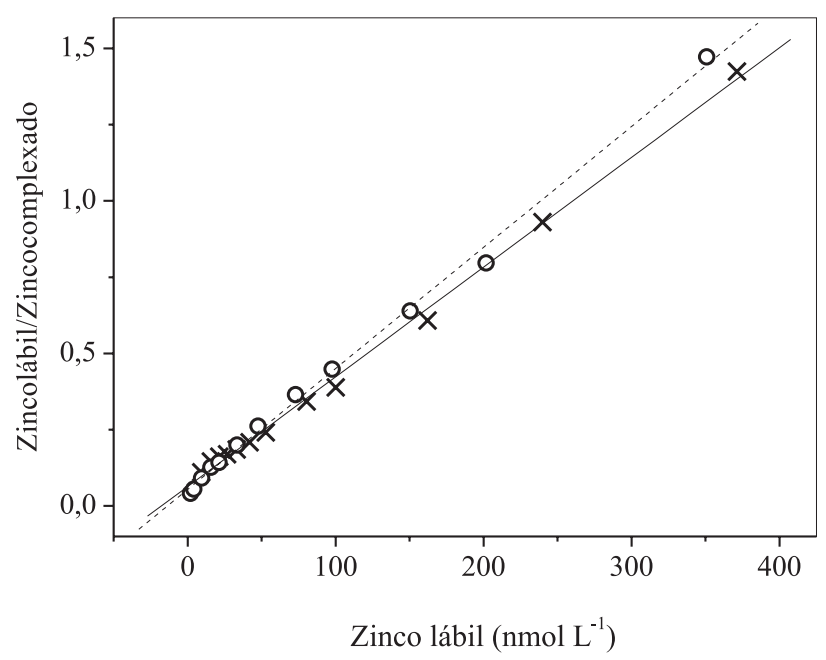

Figura 3. Determinação das capacidades de complexação, baseada na linearização de Ruzic, das amostras de água do Reservatório do Iraí, (○) amostra A e $(\times)$ amostra B. Equação da reta para cobre: amostra $A(\cdots)[C u]_{\text {labil }} /[\mathrm{Cu}]$ complexado $=0,2+7,0.10^{6 *}[\mathrm{Cu}]_{\text {labil }}(r=0,9798) ; \operatorname{amostra~B~(一)~}[\mathrm{Cu}]_{\text {labil }}[\mathrm{Cu}]$ complexado $=0,1+7,0.10^{6} *[\mathrm{Cu}]_{\text {labil }}(r=0,9963)$. (b) Equação da reta para zinco: amostra $A(\cdots)[Z n]_{\text {labil }} /[Z n]_{\text {complexado }}=0,05+4,0.10^{6 *}[\mathrm{Zn}]_{\text {labil }}(r=0,9984)$; amostra B (一) [Zn $]_{\text {labil }}\left[[Z n]_{\text {complexado }}=0,06+4,0.10^{6 *}[\mathrm{Zn}]_{\text {labil }}(r=0,9985)\right.$

Nas amostras A e B, a titulação de CC da água frente aos metais cobre e zinco forneceu a constante de estabilidade condicional ( $\left.\log \mathrm{K}^{\prime}\right)$, similar para os metais analisados, 7,6 $\pm 0,2$ para o cobre e 7,9 $\pm 0,1$ para o zinco na amostra A (teste t, $P=0,2206$ ) e $8,0 \pm 0,2$ para o cobre e 7,7 $\pm 0,1$ para o zinco, na amostra $\mathrm{B}$ (teste t, $P=0,1163$ ). No entanto, a concentração de ligantes disponíveis para o cobre foi menor, tanto na amostra A $(143,6 \pm 11,5$ nmol L $\left.\mathrm{L}^{-1}\right)$, quanto na amostra $\mathrm{B}\left(142,9 \pm 11,4 \mathrm{nmol} \mathrm{L} \mathrm{L}^{-1}\right)$, do que as encontradas para o zinco (amostra A: 252,0 $\pm 22,4 \mathrm{nmol} \mathrm{L}^{-1}$; amostra B: $278,0 \pm 24,7 \mathrm{nmol} \mathrm{L}^{-1}$ ) (teste t, $P=0,0017$ ).

Os coeficientes de correlação obtidos para as retas dos gráficos na Figura 3 (cobre: 0,980 amostra A; 0,996 amostra B; zinco: 0,998 amostra A; 0,998 amostra B) são típicos de titulações envolvendo estes dois metais. Isso evidencia que os dados gerados nas titulações apresentam elevada confiabilidade. ${ }^{32}$

Como mostra a Tabela 1, cobre e zinco apresentam afinidade similar pelo material dissolvido (teste t, $P>0,1973$ ), exceto cobre 
determinado na amostra A (teste t, $P=0,0316$ ). Nessa amostra, cobre apresentou maior afinidade pelo material particulado, que é caracterizado pela biomassa fitoplanctônica, resultante da eutrofização do ambiente. Esses resultados indicam que ambos os metais possuem afinidade pela MOD, óxidos, carbonatos, assim como pela fase coloidal. ${ }^{4} \mathrm{~A}$ fração lábil corresponde a $29 \%$ do cobre na fração dissolvida nas amostras A e B, enquanto que o análogo para o zinco está próximo de 4 e $10 \%$, respectivamente. Avaliando-se os dados de $\mathrm{CC}$, observou-se que os agentes complexantes disponíveis nas águas do Reservatório do Iraí apresentam uma maior CC para o zinco, quando comparado ao cobre. Este comportamento é explicado pela maior concentração de zinco (ZnTR), que é o dobro da concentração de cobre (CuTR) na amostra A (teste t, $P=0,0006$ ). Já, na amostra $B$ a concentração de ZnTR é 5,5 vezes maior que a concentração de CuTR (teste t, $P=0,0003$ ).

Os resultados obtidos para especiação de cobre e zinco no presente estudo são semelhantes àqueles encontrados na literatura para ambientes eutrofizados. ${ }^{16,18,33,34}$ No entanto, cabe ressaltar que a análise de especiação dos metais nos trabalhos supracitados se baseou em abordagens experimentais distintas, diferentemente deste trabalho, no qual a partir de um mesmo protocolo foi capaz de gerar informações relevantes para avaliar o comportamento e possíveis impactos associados à presença de metais em ambientes aquáticos.

\section{CONCLUSÕES}

A partir dos comportamentos observados nos voltamogramas dos sais estudados, verificou-se que $\mathrm{KNO}_{3}$ e $\mathrm{HNO}_{3}$ resultaram em menor interferência e em melhor resolução dos voltamogramas. A definição das condições experimentais como descritas tem como principais vantagens a simplicidade na realização da quantificação e o uso de um mesmo procedimento para ambos os metais. Em função dos relatos contidos na literatura, acredita-se que esta abordagem possa descrever com relativa fidelidade o comportamento de agentes complexantes frente aos metais cobre e zinco em ecossistemas aquáticos naturais. Sendo assim, a implantação da metodologia, utilizando $\mathrm{KNO}_{3}$ como eletrólito de suporte e $\mathrm{HNO}_{3}$ para preservar a amostra, é adequada para a análise de especiação de cobre e zinco empregando voltametria de redissolução anódica.

O procedimento proposto permite uma análise simples, de alta sensibilidade e precisão, atingindo limites de quantificação de 1,8 nmol L ${ }^{-1}$ para cobre e $2,1 \mathrm{nmol} \mathrm{L}^{-1}$ para zinco, além de baixos custos, para determinação desses metais. Embora o período de análise por amostra de acordo com a fração determinada seja de 30 min para fração total e total dissolvido e de $6 \mathrm{~h}$ para a fração lábil, complexada e capacidade de complexação, o limite de detecção dos elementos é bastante baixo quando comparado com a maioria de outros métodos analíticos reportados na literatura.

\section{AGRADECIMENTOS}

À Prof ${ }^{a}$. Dra ${ }^{a}$ A. T. Lombardi pela contribuição na preparação deste documento.

\section{REFERÊNCIAS}

1. Sigg, L.; Black, F.; Buffle, J.; Cao, J.; Cleven, R.; Davison, W.; Galceran, J.; Gunkel, P.; Kalis, E.; Kistler, D.; Martin, M.; Noel, S.; Nur, Y.; Odzak, N.; Puy, J.; van Riemsdijk, W.; Temminghoff, E.; Tercier-Waeber, M. L.;
Toepperwien, S.; Town, R. M.; Unsworth, E.; Warnken, K. W.; Weng, L. P.; Xue, H. B.; Zhang, H.; Environ. Sci. Technol. 2006, 40, 1934.

2. Lombardi, A. T.; Hidalgo, T. M. D.; Vieira, A. A. H.; Sartori, A. L.; Phycologia 2007, 46, 74 .

3. Buffle, J.; Tercier-Waeber, M. L.; Trac, Trends Anal. Chem. 2005, 24, 172.

4. van Hullebusch, E.; Chatenet, P.; Deluchat, V.; Chazal, P. M.; Froissard, D.; Botineau, M.; Ghestem, A.; Baudu, M.; Water, Air, Soil Pollut. 2003, $150,3$.

5. Batley, G. E.; Apte, S. C.; Stauber, J. L.; Aust. J. Chem. 2004, 57, 903.

6. Mylon, S. E.; Twining, B. S.; Fisher, N. S.; Benoit, G.; Environ. Sci. Technol. 2003, 37, 1261.

7. Bott, A. W.; Curr. Sep. 1995, 14, 24.

8. Rocha, J. C.; Rosa, A. H.; Substâncias húmicas aquáticas: interações com espécies metálicas, $1^{\mathrm{a}}$ ed., Editora da UNESP: São Paulo, 2003.

9. Wiramanaden, C. I. E.; Cullen, J. T.; Ross, A. R. S.; Orians, K. J.; Mar. Chem. 2008, 110, 28.

10. Lombardi, A. T.; Jardim, W. F.; Chem. Speciation Bioavailability 1997, 9, 27

11. Florence, T. M.; Analyst 1986, 111, 489.

12. Bruland, K. W.; Rue, E. L.; Donat, J. R.; Skrabal, S. A.; Moffett, J. W.; Anal. Chim. Acta 2000, 405, 99

13. Xue, H. B.; Sigg, L.; Anal. Chim. Acta 1998, 363, 249.

14. Monticelli, D.; Ciceri, E.; Dossi, C.; Anal. Chim. Acta 2007, 594, 192.

15. Meylan, S.; Odzak, N.; Behra, R.; Sigg, L.; Anal. Chim. Acta 2004, 510, 91.

16. Velasquez, I. B.; Jacinto, G. S.; Valera, F. S.; Mar. Pollut. Bull. 2002, 45, 210.

17. Knauer, K.; Ahner, B.; Xue, H. B.; Sigg, L.; Environ. Toxicol. Chem. 1998, 17, 2444

18. Xue, H. B.; Gachter, R.; Sigg, L.; Aquat. Sci. 1997, 59, 176.

19. Xue, H. B.; Kistler, D.; Sigg, L.; Limnol. Oceanogr. 1995, 40, 1142.

20. Skoog, D.; Holler, F. J.; Nieman, T. A.; Princípios de análise instrumental, $5^{\text {a }}$ ed., Bookman: Porto Alegre, 2002.

21. Harris, D. C.; Quantitative chemical analysis, $5^{\text {th }}$ ed., W.H. Freeman: New York, 1998.

22. Wang, J.; Stripping Analysis Principles, Instrumentation, and Applications, VCH: Deerfield Beach, 1985.

23. Tyszczuk, K.; Korolczuk, M.; Grabarczyk, M.; Talanta 2007, 71, 2098.

24. Ruzic, I.; Anal. Chim. Acta 1982, 140, 99.

25. Soares, H. M. V. M.; Vasconcelos, M. T. S. D.; Anal. Chim. Acta $\mathbf{1 9 9 5}$ 303, 255.

26. Campos, M.; Bendo, A.; Viel, F. C.; Quim. Nova 2002, 25, 808.

27. Benoit, G.; Hunter, K. S.; Rozan, T. F.; Anal. Chem. 1997, 69, 1006.

28. Perdue, E. M.; Ritchie, J. D. Em Dissolved organic matter in fresh waters; Drever, J. I., ed.; Elsevier-Pergamon: Oxford, 2003.

29. Templeton, D. M.; Ariese, F.; Cornelis, R.; Danielsson, L. G.; Muntau, H.; van Leeuwen, H. P.; Lobinski, R.; Pure Appl. Chem. 2000, 72, 1453.

30. Lenoble, V.; Garnier, C.; Masion, A.; Ziarelli, F.; Garnier, J. M.; Anal. Bioanal. Chem. 2008, 390, 749.

31. Sodré, F. F.; Peralta-Zamora, P. G.; Grassi, M. T.; Quim. Nova 2004, 27, 695.

32. Scarponi, G.; Capodaglio, G.; Barbante, C.; Cescon, P. Em Element Speciation in Bioinorganic Chemistry; Caroli, S., ed.; John Wiley \& Sons: New York, 1996

33. Xue, H. B.; Sigg, L.; Anal. Chim. Acta 1994, 284, 505.

34. Alonso, E.; Santos, A.; Callejon, M.; Jimenez, J. C.; Chemosphere 2004, $56,561$. 